\title{
NUEVAS CONSIDERACIONES SOBRE LA GEOGRAFÍA Y LA PRESENCIA CONVENTUAL EN LA ESPAÑA MODERNA. OTRAS FACETAS MÁS ALLÁ DE LA CONCENTRACIÓN URBANA
}

\author{
POR \\ ÁNGELA ATIENZA LóPEZ \\ Prof. Titular de Universidad, Historia Moderna. Universidad de La Rioja
}

\section{RESUMEN}

Los estudios que se han aproximado a la caracterización del mapa de la presencia conventual en la España moderna han subrayado siempre una faceta: su elevado grado de concentración. Este trabajo pretende incidir en otras dimensiones de esa presencia conventual que normalmente han quedado más olvidadas. Junto a esa concentración, la dispersión fue también una realidad constitutiva del mapa conventual español de la modernidad. y es que se fueron fundando muchos, muchísimos conventos y no cabe minusvalorar ni olvidar la existencia de otros muchos centenares de cenobios, además de los que se acumularon en esas ciudades saturadas de presencia conventual. La exposición de esta faceta se acompaña del análisis explicativo de la misma atendiendo tanto a la presión de los fundadores y a la incidencia de sus particulares intereses, como a las consideraciones y pautas que marcaron las propias órdenes religiosas.

PALABRAS CLAVE: Órdenes religiosas, clero regular, conventos, geografía, fundadores, España moderna.

\section{NEW APROACHES ON CONVENTUAL GEOGRAPHY IN EARLY MODERN SPAIN. NEW POINTS OF VIEW BEYOND URBAN CONCENTRATION}

\begin{abstract}
Previous essays that have attempted any approach to map the spread of convents in Early Modern Spain have always pointed out their high degree of concentration. This article tries to show other perspectives on the geography of convents. Besides
\end{abstract}


concentration, dispersal is also a reality in the map of convents in Spain during the early modern period. Foundations were so numerous that we cannot forget the many other convents set up in other places rather than the towns saturated of them. This is the argument that will be explained in the pages below, considering the founders particular interests and also the norms established by the religious orders.

KEY WORDS: Religious orders, convents, geography, founders, Early Modern Spain.

Recibido/Received 22-01-2008

Aceptado/Accepted 13-04-2008

A día de hoy podemos afirmar que conocemos con un notable grado de precisión la realidad de la presencia conventual en la España de finales del Antiguo Régimen, su magnitud y su geografía. La información proporcionada por los censos de la segunda mitad del siglo XVIII y los estudios que a partir de ellos se han realizado nos han permitido aproximarnos con bastante fidelidad a este escenario de una España que acabó estando ocupada por cientos y cientos de monasterios y conventos de frailes y de monjas ${ }^{1}$.

${ }^{1}$ P. Carasa Soto publicó un estudio detallado de los datos del censo de Ensenada, y aunque, como es sabido, quedan referidos únicamente a los territorios de la Corona de Castilla, también aporta los datos de 1768 correspondientes al censo de Aranda, que ya refleja la situación en las dos Coronas. Por mi parte he reproducido los datos de un sumario de carácter general de 1762 menos conocido. Y, finalmente, el censo de 1787 de Floridablanca aporta una fotografía bastante precisa de la España conventual, aunque es cierto que contiene algunos errores y que naturalmente no incorpora las casas de jesuitas, ya expulsados para esas fechas. Las referencias bibliográficas concretas son las siguientes: P. CARASA Soto, Censo de Ensenada, 1756, Madrid, 1993. Colección Alcabala del Viento. Repite la información en un trabajo que, a pesar de su título, ofrece en sus tablas también los datos referidos al conjunto del clero regular, masculino y femenino, y que aporta además unos útiles mapas de la presencia y entidad de las distintas órdenes religiosas de clero regular masculino, «El clero regular masculino en la Corona de Castilla en 1756», en Monjes y Monasterios españoles, Actas del Simposium (1-5 de septiembre de 1995), t. II, Estudios Superiores del Escorial, Madrid, 1995, pp. 1061-1112. Los datos de 1762 proceden de RAH 11/9389, $\mathrm{n}^{\circ}$ 492. Mapa puntual, que manifiesta las Armadas de mar y tierra que tiene la Magestad Catholica del Rey N. S (que Dios guarde) hasta el principio del año de 1762: Se expresan todos los regimientos, con los esquadrones, compañías y hombres de que se componen...: asi mismo se describen todas las provincias y conventos de religiosos y religiosas que hay en todo el Reyno, como el número de Parroquias, y las Rentas de sus Arzobispados, y Obispados. Reimpreso en Madrid. Año de 1762. Los he reproducido en A. ATIENZA LóPEZ, Tiempos de conventos. Una historia social de las fundaciones en la España Moderna. Madrid, 2008. Reproduzco también en el mismo trabajo los datos del censo de Floridablanca, tomados del Censo español executado por orden el Rey comunicada por el Excelentísimo Señor Conde de Floridablanca, primer secretario de Estado y del Despacho, en el año de 1787. Imprenta Real. Edición facsímil, Madrid, 1987. Pueden verse además los extractos de datos que ofrece J. SAEZ MARín, Datos sobre la Iglesia española contemporánea, 17681868. Madrid, 1975.

Por su parte, F. J. Campos y Fernández de Sevilla también ha publicado recientemente el detalle de los datos referidos a conventos femeninos a partir de los distintos censos y recuentos demográficos del siglo XVIII. F. J. CAMPOS y FERnÁndEZ DE SEVILlA, «El monacato femenino de la España de la Ilustración en cifras», en La clausura femenina en España. Actas del Simposium, v. I, San Lorenzo del Escorial, 2004, pp. 7-82.

Hispania Sacra, LXI

123, enero-junio 2009, 51-75, ISSN: 0018-215-X 
Las correcciones y ajustes que he podido efectuar sobre el censo más completo, el de Floridablanca, añadiendo las casas de jesuitas existentes antes de su expulsión así como otros cenobios que he logrado comprobar que no quedaron apuntados en el censo referido me han permitido fijar en 3.260 los establecimientos de regulares que llegó a haber en España en su momento de mayor expansión ${ }^{2}$. De ellos 2.202 serían masculinos y 1.058 corresponderían a claustros femeninos. Con toda la provisionalidad que sea aconsejable y se acepte, considero que con estas magnitudes puede quedar perfilada la entidad de la España conventual en lo que fueron sus máximas dimensiones.

Más de tres mil conventos fueron muchos conventos, sin duda. Pero su reparto por la geografía española no fue en absoluto uniforme. La panorámica general de esta distribución y sus rasgos más sobresalientes son bien conocidos ${ }^{3}$. La monografía del equipo dirigido por E. Ruiz Martínez Ruiz presenta sus referencias fundamentales en una síntesis reciente, completa y bien articulada a la que cabe remitir ${ }^{4}$. Por ello no entraré en detalles al respecto más allá de lo estrictamente imprescindible y, sobre todo, porque el objetivo de este trabajo es precisamente incidir sobre algunos elementos que han recibido menor atención en la historiografía general sobre la cuestión, proponer nuevas consideraciones, plantear alguna otra dimensión del tema que ha quedado más ensombrecida y subrayar en él algunas otras cuestiones desde una perspectiva que ha sido menos transitada y que en mi opinión no sería menos importante.

Todos los trabajos que se han aproximado al estudio y a la caracterización del mapa de la presencia conventual en la España Moderna han subrayado una

2 Debo indicar que en estas cifras no incluyo las casas pertenecientes a las órdenes militares ni masculinas ni de comendadoras, ni tampoco los beaterios que contempla el censo de Floridablanca. Las consideraciones pertinentes para el establecimiento de estas cifras, en A. ATIEnZA López, Tiempos de conventos...op. cit., pp. 27 ss.

${ }^{3}$ Distintos trabajos de perspectiva más general o más particular han podido ir ofreciendo sus características más destacadas. Pueden verse las referencias citadas arriba de P. Carasa Soto y F. J. Campos y Fernández de Sevilla. Habría que añadir también, el trabajo de F. RuIz MARTín, «Demografía eclesiástica hasta el siglo XIX», en DHEE, t. II, pp. 682-733. Y el de M. BARRIO GoZALO, «El clero regular en la España de mediados del siglo XVIII a través de la Encuesta de 1764», Hispania Sacra, 47 (1995), pp. 121-169. Entre los estudios sobre zonas concretas de la Península, cabe destacar, para el reino de Sevilla, A. L. López MARTínez, La economía de las órdenes religiosas en el Antiguo Régimen. Sus propiedades y rentas en el Reino de Sevilla, Sevilla, 1992 La zona de Castilla-La Mancha, en J. C. VizUETE MENDOZA, «Las órdenes religiosas», en F. GARcía GonZÁlez (Coord), Castilla La Mancha en la Edad Moderna, Ciudad Real, 2004, pp. 237-256. Y el caso de Aragón, en A. AtiEnZA LóPEZ, «La expansión del clero regular en Aragón durante la Edad Moderna. El proceso fundacional», Revista de Historia Moderna, Anales de la Universidad de Alicante, 21 (2003), pp. 57-76. Para el territorio catalán, J. BADA y G. SAMPER (Dirs); Catalonia Religiosa. Atles històric: dels origens als nostres dies. Barcelona, 1991. Y, por supuesto, no pueden dejar de citarse las contribuciones contenidas en los diferentes volúmenes de la Historia de las diócesis españolas que viene editando la BAC en los últimos años.

${ }^{4}$ E. Martínez Ruiz (Dir), El peso de la Iglesia. Cuatro siglos de Órdenes Religiosas en España, Madrid, 2004, principalmente, capítulos III y IV. 
faceta: su elevado grado de concentración, la aglomeración de claustros en determinadas ciudades que daría por resultado una red conventual excepcionalmente desequilibrada, una red que primaría los centros urbanos y los núcleos de población más importantes 5 . Las tendencias fundacionales que las órdenes mendicantes manifestarían ya desde el siglo XIII y su preferencia por el medio urbano $^{6}$ proseguiría durante los siglos de la modernidad y sería también la orientación que marcaría la difusión y la expansión de los clérigos regulares.

Por supuesto no pretendo poner en cuestión esta caracterización, que es perfectamente cierta. Realmente los datos no dejan margen para la duda. Sólo diez y ocho ciudades llegarían a sumar nada menos que 680 conventos; entre ellas reunirían así alrededor de la quinta parte de los conventos que poblaban España en la segunda mitad del siglo XVIII ${ }^{7}$.

Es indiscutible, por tanto, que el grado de concentración del clero regular fue realmente notable y que hubo núcleos de población auténticamente sobresaturados. Sin embargo, los historiadores que hemos estudiado estas cuestiones, quizás abrumados precisamente por estas magnitudes de aglomeración, hemos arrinconado y relegado otras facetas que estuvieron también presentes en la distribución y en la geografía conventual española y hemos desatendido otras perspectivas de análisis de la misma realidad.

$\mathrm{Y}$ es que se fueron fundando muchos, muchísimos conventos. El proceso de expansión de los regulares, concentrado en los siglos XVI y XVII, fue desbordante, y no cabe minusvalorar ni olvidar la existencia de otros muchos centenares de cenobios, además de los que se acumularon en esas ciudades rebosadas de presencia conventual. No podemos marginar la importancia del gran número de localidades que, tanto en la Corona de Castilla como en la de Aragón, acogieron sólo uno o dos conventos. Es ésta una perspectiva del tema que apenas ha sido considerada por la historiografía; recientemente he apuntado apenas un esbozo básico que con-

${ }^{5}$ Cualquiera de los trabajos citados en las notas anteriores ha recalcado esta característica. Yo misma lo he subrayado con énfasis en el estudio monográfico que realicé sobre la presencia del clero regular en el Aragón de la Edad Moderna. De la misma manera, el arraigo de esta idea se ha plasmado también en las síntesis de historia de España, su clero y su Iglesia, que se escriben y publican fuera. Así, puede verse en uno de los trabajos más recientes, Ph. Loupès, «L'Église dans les villes espagnoles», en Les societés urbanines au XVIIe siècle. Anglaterre, France, Espagne. Paris, 2007, pp. 191-204.

${ }^{6}$ En este terreno, son ya clásicos los trabajos de J. LE GoFF, «Apostolat mendiant et fait urbaine dans la France Médiévale: l'implantation géographique et sociologique des ordres mendiants aux XIIIXV siècles», Annales E.S.C, 1968, pp. 335-352, y «Ordres mendiants et urbanisation dans la France Médiévale», Annales E.S.C, 1970, pp. 954-965. También, A. LinAGE CondE y A. OLIVER, «Las órdenes religiosas en la Baja Edad Media: los mendicantes», en R. GARcía VillosladA, Historia de la Iglesia en España, vol. II, 2, Madrid, 1979.

${ }^{7}$ La relación es la siguiente: Sevilla con 68 conventos, Madrid con 64, Valencia y Valladolid con 49 cada una, Barcelona con 47, Zaragoza con 44, Córdoba con 43, Toledo y Granada con 41 en cada caso, Salamanca con 38, Alcalá de Henares con 31, Palma de Mallorca con 27, Málaga con 25, Murcia con 24, Burgos y Segovia con 23 cada una, Jerez de la Frontera con 22 y Écija con 21.

Hispania Sacra, LXI

123, enero-junio 2009, 51-75, ISSN: 0018-215-X 
templa esta realidad ${ }^{8}$, pero considero que exige un desarrollo más fundamentado y argumentado y que merece un mayor esfuerzo explicativo.

El planteamiento es el siguiente: la concentración y la dispersión fueron ambas realidades constitutivas del mapa conventual español de la modernidad. No constituyen facetas contradictorias. Fueron tantos los conventos, tan grande fue su número que tal magnitud dio de sí y de sobra para que muchos se concentraran en unas pocas localidades, pero también muchos otros se repartieran por otros núcleos de población. Fueron tantos los conventos que el fenómeno de concentración pudo convivir y coexistir con esta otra realidad de dispersión. Expresado en números y cifras: junto a las 680 comunidades religiosas mencionadas que estaban instaladas en sólo diez y ocho ciudades, todavía quedaban nada menos que unas 2.580, según mis datos.

El dibujo de la España conventual incorpora también un gran número de núcleos que acogieron sólo uno o dos conventos de frailes o monjas. En el cuadro 1 he organizado la información referida al número de localidades que tuvieron uno, dos, tres... hasta siete conventos, y el número de aquellas que fueron admitiendo más, mientras que en el cuadro 2 presento el número de conventos, diferenciando entre conventos masculinos y conventos femeninos, que estuvieron presentes en las poblaciones que acogieron uno o más conventos.

\section{CUADRO 1. Número de localidades, en función del número de conventos que llegaron a albergar (*)}

\begin{tabular}{|l|c|}
\hline Número conventos & Número localidades \\
\hline $\begin{array}{l}\text { Con } 1 \text { convento } \\
\text { (convento único) }\end{array}$ & 745 \\
\hline Con 2 conventos & 168 \\
\hline Con 3 conventos & 88 \\
\hline Con 4 conventos & 41 \\
\hline Con 5 conventos & 25 \\
\hline Con 6 conventos & 25 \\
\hline Con 7 conventos & 11 \\
\hline Entre 8 y 10 conventos & 26 \\
\hline Entre 11 y 15 conventos & 26 \\
\hline Entre 16 y 20 conventos & 7 \\
\hline Con más de 20 conventos & 18 \\
\hline TOTAL & 1.180 \\
\hline
\end{tabular}

(*) Elaboración propia.

${ }^{8}$ A. Atienza López, Tiempos de conventos... op . cit., pp. 47-48. 
CUADRO 2. Número de conventos (de frailesy monjas) en localidades con uno o más conventos $(*)$

\begin{tabular}{|l|r|r|r|r|r|}
\hline Presencia en localidades & Frailes & $\mathbf{( \% )}$ & Monjas & $\mathbf{( \% )}$ & Total \\
\hline $\begin{array}{l}\text { Con } 1 \text { convento } \\
\text { (convento único) }\end{array}$ & 626 & 28,43 & 119 & 11,25 & 745 \\
\hline Con 2 conventos & 228 & 10,36 & 108 & 10,21 & 336 \\
\hline Con 3 conventos & 158 & 7,18 & 106 & 10,01 & 264 \\
\hline Con 4 conventos & 105 & 4,77 & 59 & 5,58 & 164 \\
\hline Con 5 conventos & 82 & 3,73 & 43 & 4,07 & 125 \\
\hline Con 6 conventos & 101 & 4,58 & 49 & 4,64 & 150 \\
\hline Con 7 conventos & 55 & 2,49 & 22 & 2,08 & 77 \\
\hline Entre 8 y 10 conventos & 138 & 6,27 & 98 & 9,26 & 236 \\
\hline Entre 11 y 15 conventos & 219 & 9,94 & 113 & 10,68 & 332 \\
\hline Entre 16 y 20 conventos & 94 & 4,26 & 61 & 5,76 & 155 \\
\hline Con más de 20 conventos & 396 & 17,99 & 280 & 26,46 & 676 \\
\hline TOTAL & 2202 & 100 & 1058 & 100 & 3260 \\
\hline
\end{tabular}

(*) Elaboración propia.

Como se ve, el total de lugares que admitieron alguna comunidad religiosa se cifra en 1.180, lo que nos puede ofrecer una panorámica nueva de la presencia de los regulares: extensa, dilatada, amplia. Si bien no puede negarse la existencia de espacios más o menos grandes -sobre todo en el Norte peninsularque carecieron de cualquier residencia conventual ${ }^{9}$, realmente puede mantenerse la tesis de que una parte importante de la geografía española pudo ver más o menos próxima la presencia de algún convento o monasterio.

Ciertamente, ante esta realidad de mayor dispersión de la ubicación conventual en la que estamos incidiendo cabe considerar que la idea tan asentada de que la distribución del clero regular agravaría el desequilibrio ya existente del reparto del clero secular quizás merezca alguna matización. Es posible valorar que muchos conventos pudieron, al contrario, aliviar situaciones geográficas de desasistencia espiritual o ayudar a cubrir escenarios que pudieran presentar precariedad en la atención pastoral ${ }^{10}$, y sí parece claro que las órdenes religiosas

\footnotetext{
${ }^{9}$ Según es conocido y ha sido subrayado suficientemente en la síntesis de carácter general más reciente. E. MARTínez RuIZ (Dir), El peso de la Iglesia...

${ }^{10}$ Aunque en un sentido más amplio, cabría recordar el caso andaluz, estudiado por A. Morgado, que ha podido poner de manifiesto cómo en estas tierras la red parroquial fue bastante laxa y la presen- 
tuvieron un papel importante en las áreas rurales y en los ámbitos en los que las estructuras parroquiales no llegaban a satisfacer las demandas de servicios religiosos y de atenciones espirituales que, por otra parte, la misma Iglesia postridentina estaba alimentando. Por otra parte, no se puede olvidar que las ideas de precariedad y desasistencia, lo mismo que las ideas de abundancia y saturación son, en buena medida, relativas y contienen un nivel de subjetividad importante: la época, los tiempos, los contextos sociales, culturales... inciden en su determinación y en la valoración de estas circunstancias.

Los elevados grados de aglomeración de comunidades religiosas en algunas poblaciones en los que tradicionalmente ha insistido la historiografía coexistieron con esta otra realidad en la que se ha hecho bastante menos incidencia: la existencia de muchos conventos solitarios, únicos en el espacio en el que se instalaron, dispersos por distintos puntos del territorio español y, desde luego, hay que apreciar que las comunidades masculinas que se establecieron en localidades carentes de ninguna otra presencia conventual supusieron una aportación muy importante a las necesidades de asistencia religiosa de los fieles de la localidad y del entorno. Serían 626 los cenobios de frailes (ver cuadro 2) que no compartieron su existencia con ningún otro en las localidades donde se instalaron. Pero, a mayor abundancia de esta consideración, habría que sumar también aquellos otros conventos masculinos que -como tales conventos de frailes- fueron únicos en su demarcación, es decir, aquellos casos en los que el resto de los claustros de la localidad eran femeninos. Y en este punto, debemos señalar que de esos 108 conventos de monjas que refiere el cuadro 2 que estuvieron asentados en localidades donde compartieron su presencia con otro cenobio más, todos excepto cuatro (dos en Eibar y dos en Loeches) estuvieron acompañados de una comunidad masculina. Y por lo que se refiere a las localidades que llegaron a acoger tres conventos, también pueden referirse los ejemplos de aquellas en las que entre las tres comunidades, sólo una fue masculina, como sucedió en las poblaciones de Aguilar (Córdoba), Almendral, Almendralejo, Fuente de Cantos y Medellín (en Badajoz), en las localidades guipuzcoanas de Azoitia, Mondragón, Oñate, Tolosa y Zarauz, así como en Belvís de Monroy (Cáceres), en El Toboso (Toledo), en Mula (Murcia), en Oliva (Valencia), en Piedrahita (Ávila), en Durango (Vizcaya) y en Villanueva del Arzobispo (Jaén). Y ya entre las localidades que llegaron a alcanzar los cuatro conventos, sólo conozco una -Villarrobledo (Albacete) - en la que la presencia masculina fue única, compartida en este caso con tres cenobios femeninos.

cia de regulares abundante, concluyendo que «la actividad espiritual del clero regular contribuirá a paliar poderosamente, qué duda cabe, las insuficiencias del cuerpo parroquial». A. MorgAdo GARCíA, «La estructura eclesiástica andaluza durante el Antiguo Régimen», en A. L. CorTÉs PEÑA, y M. L. LóPEZ-GuAdaluPE; Estudios sobre Iglesia y Sociedad en Andalucía en la Edad Moderna. Granada, 1999, pp. 113-136. 
También hay que señalar, por lo demás, que en la cifra de 745 comunidades religiosas que monopolizaron ubicación no sólo se incluyen los monasterios pertenecientes a las órdenes monásticas de fundación medieval, enclavados en el medio rural, que, por otra parte, a finales del Antiguo Régimen ya no sumaban proporcionalmente tantos, y no se puede olvidar, además, que cistercienses y benedictinos tampoco despreciaron las grandes aglomeraciones para instalar algunas de sus comunidades e, incluso, como es sabido, en el transcurso de la Edad Moderna algunas de estos centros monásticos cambiaron su ubicación aproximándose a los núcleos urbanos ${ }^{11}$.

Este estudio quedaría incompleto sin plantear, aunque sea brevemente, una mención específica a la dinámica y rasgos de la ubicación de las órdenes y claustros femeninos que también proliferarían por la geografía peninsular en los siglos modernos.

1.026 conventos de religiosas es la cifra que resulta del censo de Floridablanca $^{12}$. Unos pocos más -1.058 - son los que he podido contabilizar contrastando esos datos y otras informaciones; es decir, en torno a una tercera parte del total de las comunidades religiosas existentes a fines del Antiguo Régimen correspondían a ramas femeninas, y poco más o menos esta relación se mantendría en todas las regiones, lo que viene a significar que, con esta proporción indicada, la distribución geográfica de los conventos de monjas sería muy similar a la que hemos ido viendo para los frailes. Es decir, los desequilibrios entre diferentes reinos y territorios mantendrían su presencia. Las únicas zonas que se apartarían más sensiblemente del reparto señalado serían, por arriba, Extremadura que casi igualaría en número sus conventos masculinos y femeninos, y el territorio vasco, en el que los claustros de monjas (59) superarían a los masculinos (47). Por abajo, sería Cataluña la región que presente un porcentaje de establecimientos femeninos más reducido, de entorno al $18 \%$.

Por otra parte, un análisis de conjunto de la ubicación conventual femenina permite observar que la gran mayoría de los claustros de monjas estuvieron acomodados en localidades que contaron con, al menos, otra comunidad religiosa.

${ }^{11}$ Algunos de ellos, los femeninos, en aplicación de los decretos tridentinos que, por razones de seguridad, consideraron la conveniencia de los traslados. Las «Providencias sobre la clausura, y custodia de Monjas», capítulo V, sesión XXV, establecían: «Y por quanto los monasterios de Monjas, fundados fuera de poblado, están expuestos muchas veces por carecer de toda custodia, á robos, y otros insultos de hombres facinerosos; cuiden los Obispos, y otros superiores, si les pareciere conveniente de que se trasladen las Monjas desde ellos á otros monasterios nuevos, ó antiguos, que estén dentro de las ciudades, ó lugares bien poblados; invocando también para esto, si fuese necesario, el auxilio del brazo secular. Y obliguen á obedecer con censuras eclesiásticas á los que lo impidan, ó no obedezcan». Cito por El Sacrosanto y Ecuménico Concilio de Trento, traducido al idioma castellano por don Ignacio López de Ayala, $2^{a}$ ed. Madrid, 1785.

12 Recuerdo que no están consideradas en esta cifra las casas pertenecientes a comendadoras ni tampoco los beaterios que contempla el censo.

Hispania Sacra, LXI

123, enero-junio 2009, 51-75, ISSN: 0018-215-X 
Del total de los 1.058 conventos femeninos que he podido fichar sólo 119 fueron cenobios únicos, que ocuparon de forma exclusiva una población (véase el cuadro 2). El resto de los establecimientos de monjas se vieron acompañados por, al menos, otra comunidad que siempre fue masculina, como hemos avanzado arriba, y que en muchos casos daría respaldo y atención a la casa femenina. Únicamente conozco dos localidades que escaparon de esta regla: las ya señaladas Eibar y Loeches, con dos conventos cada una y los dos femeninos en ambos casos.

En general, su distribución no presentará demasiadas diferencias respecto a lo ya visto para el conjunto del clero regular y específicamente también para los conventos masculinos. Por un lado, será apreciable la abundancia de claustros de religiosas en un número reducido de localidades. Abajo ofrecemos la relación de estas ciudades que llegaron a acoger diez o más conventos femeninos y, como vemos, se repiten las mismas que integraban el listado de las más nutridas de cenobios. Sólo estas trece poblaciones concentrarían en torno al $22 \%$ del conjunto de comunidades de monjas.

\section{CUADRO 3. Localidades con diez o más conventos femeninos a mediados del siglo XVIII (*)}

\begin{tabular}{|l|l|c|}
\hline Región & \multicolumn{1}{|c|}{ Localidad } & Número total de conventos \\
\hline Madrid & Madrid & 30 \\
\hline Andalucía & Sevilla & 27 \\
\hline Castilla-León & Valladolid & 23 \\
\hline Valencia & Valencia & 22 \\
\hline Castilla-León & Toledo & 22 \\
\hline Andalucía & Córdoba & 20 \\
\hline Andalucía & Granada & 19 \\
\hline Cataluña & Barcelona & 17 \\
\hline Aragón & Zaragoza & 16 \\
\hline Castilla-León & Salamanca & 13 \\
\hline Baleares & Palma de Mallorca & 11 \\
\hline Andalucía & Málaga & 10 \\
\hline Castilla-León & Burgos & 10 \\
\hline
\end{tabular}

(*) Elaboración propia.

Por otro lado, y al lado de este apreciable nivel de concentración, también el examen específico de la distribución y ubicación de los conventos femeninos 
nos permite poner de manifiesto otra realidad. Si marginamos esos 240 conventos que se situaron en las mencionadas trece ciudades que aparecen en el cuadro 3, todavía en el mapa conventual femenino hispano de finales del Antiguo Régimen se apuntaban 818 establecimientos poblados de religiosas, y sí parece revelarse un cierto grado de dispersión.

Ciertamente, retornando a los planteamientos generales, la imagen de una presencia conventual y monástica extensa y dilatada que estamos subrayando en el estudio constituyó una realidad que se iría construyendo y creciendo a medida que avanzaba el tiempo, una realidad más propia del mundo moderno, más marcada a finales del Antiguo Régimen que a finales de la Edad Media, cuando los grados de concentración en los núcleos urbanos y en las localidades más populosas fueron mayores. A estas poblaciones destacadas se dirigían las miras de las distintas órdenes religiosas, pero una vez cubierto el objetivo de instalación en ellas, lógicamente la expansión de la familia religiosa buscaba otros acomodos y se encaminaba a núcleos de importancia menor, dado que la norma de comportamiento habitual entre las órdenes fue la de no duplicar cenobios y considerar suficiente una comunidad religiosa por locali$\operatorname{dad}^{13}$.

Por lo tanto, entre las explicaciones de esta realidad que estamos dibujando hay que incorporar la propia dinámica evolutiva de las distintas órdenes religiosas en sus fases de expansión. Las órdenes mendicantes más antiguas ya tenían, al comenzar la Edad Moderna, colocados sus bastiones conventuales en los enclaves urbanos más importantes. Pondremos sólo un ejemplo: el de la orden de Predicadores. Antes de 1450, los frailes dominicos ya habían abierto casa en alrededor de 69 localidades ${ }^{14}$. Los núcleos de población más destacados de la geografía peninsular habían sido los elegidos en general, localidades muchas de ellas que también estaban recibiendo la entrada de otras órdenes mendicantes y que continuarían posteriormente estableciendo otros claustros. Es cierto que los padres dominicos tardarían más en abrirse paso definitivo en Asturias y en Cantabria, pero no es éste el caso de la prolífica orden franciscana, por ejemplo, que desde muy pronto comenzó su instalación también en los enclaves destacados de estas demarcaciones del norte peninsular.

Lo cierto es que una vez consolidados los conventos en las localidades más populosas, estas órdenes encaminaron sus pasos a otros lugares, empezando así

${ }^{13}$ Sí sabemos que en algunas de las grandes ciudades hubo órdenes religiosas que llegaron a duplicar, triplicar y a veces más, sus establecimientos, como en Sevilla o en Madrid, pero se trató de un número muy reducido de casos.

${ }^{14} \mathrm{El}$ dato lo refiero a los conventos que fueron fundados antes de 1450 y que pervivieron a finales del Antiguo Régimen. Lógicamente, es posible que algún otro convento pudiera abrirse en ese espacio temporal pero no sobreviviera hasta la exclaustración.

Hispania Sacra, LXI

123, enero-junio 2009, 51-75, ISSN: 0018-215-X 
a configurar lo que sería con el tiempo una red conventual más amplia, extendida y dispersa ${ }^{15}$.

Pero en la explicación de esta realidad deben incorporarse más factores que los que dependen sólo de la dinámica de las órdenes religiosas, también hay que dirigir la vista en otras direcciones. Hay que convertir en objeto de estudio, en primer lugar, la participación en el proceso de los fundadores de todas estas comunidades religiosas, y en este sentido es necesario considerar cuál fue el alcance y la incidencia de los intereses particulares y personales de mecenas y promotores de las fundaciones conventuales. Hay que enfocar, en segundo lugar, a la política que diseñaron otras órdenes religiosas de nueva creación y protagonistas de la proliferación conventual de la Edad Moderna. Y, en tercer lugar, debemos también atender a lo que supuso la conflictividad y las campañas de obstrucción que generaron muchas pretensiones fundacionales o, en cualquier caso, a la incidencia que pudo tener la previsión de una segura oposición. En ocasiones confluirían las dos últimas variables explicativas. Pienso que en estos frentes es donde es posible encontrar las razones que nos ayuden a explicar el por qué de la localización de muchos conventos, sobre todo el por qué de su instalación en ocasiones en localidades de una importancia muy secundaria y en definitiva, las razones de esa realidad dispersa que estuvo presente también en la cartografía de la presencia de los regulares.

\section{LA INCIDENCIA DE LOS INTERESES PARTICULARES}

No resulta fácil determinar qué factores estuvieron detrás de las decisiones de instalación de una comunidad religiosa en un lugar determinado. Conocemos el final del proceso - una orden religiosa se establece en tal lugar y, normalmente, permanecerá en él hasta la exclaustración-, pero no siempre tenemos información puntual del camino seguido hasta llegar ahí.

La política diseñada por las órdenes religiosas explica sólo una parte de las fundaciones; como hemos señalado, casi todas querían instalarse en las capitales importantes y en las localidades populosas, prósperas y dinámicas, en estos casos, con o sin mecenas o patronos que facilitaran la tarea. Pero una vez alcanzado este objetivo, e incluso mientras duraba su consecución, la expansión sub-

\footnotetext{
15 También en el caso de Italia se ha podido confirmar esta tendencia por parte de las órdenes religiosas a multiplicar el número de sus asentamientos extendiendo su iniciativa pastoral particularmente desde fines del siglo XVI por los espacios geográficos que permanecían sin ocupar desde los tiempos tardomedievales. Puede verse al respecto, R. RUSCONI, «Gli ordini religiosi maschili dalla Contrariforma alle sopressioni settecentesche. Cultura, predicazione, misioni», en M. Rosa (a cura di); Clero e società nell'Italia moderna. Roma, 1997. Págs. 207-274. Y, G. FRAGNITO, «Gli ordini religiosi tra Riforma e Controriforma», en la misma obra coelctiva, págs. 115-206.
} 
siguiente de la orden tuvo mucho que ver con las solicitudes para fundar que recibían y las peticiones que les llegaban, bien de distintos particulares, normalmente aristócratas y/o representantes de las élites y las oligarquías locales, o miembros del clero, bien de instancias concejiles que también deseaban levantar un convento en sus términos.

En definitiva, la localización de los conventos no estuvo determinada solamente por una lógica cuantitativa (mayor población) y por una orientación urbana, sino también -y mucho- por las demandas y los intereses de aquellos que fueron importantes promotores y fundadores. Por eso, porque el proceso de expansión conventual tuvo bastante que ver con intereses particulares en demasiadas ocasiones, la presencia de claustros fue más extensa y en parte incluso caprichosa de lo que se suele resaltar. Procuraremos verlo con algo más de detalle en las páginas siguientes.

Intereses en buena medida particulares estuvieron detrás de la actividad fundacional de las grandes familias de la aristocracia, que reclamaban a las órdenes religiosas su presencia en enclaves pertenecientes a sus estados señoriales. Los intereses señoriales marcaron muchas veces las decisiones fundacionales y orientaron la elección de los lugares de asentamiento. Es cierto que muchas de estas familias convirtieron las localidades emblemáticas de sus estados en auténticas villas o ciudades conventuales, y que buscaron su engrandecimiento entre otras fórmulas a través de la promoción en ellas de distintos cenobios $^{16}$. Pero también es cierto que junto a esta tendencia a privilegiar alguna/s de sus poblaciones más significativas ${ }^{17}$, se desplegó una actividad fundacional más puntual, atrayendo comunidades religiosas y colocando así bas-

\footnotetext{
16 A. Bonet Correa, en su clasificación de ciudades del Renacimiento y del Barroco, y junto a las ciudades burocráticas, las episcopales, los núcleos industriales, destaca el prototipo que el denomina «ciudades ducales y de patronazgo»: un nuevo tipo de ciudad nacido en el siglo XVI. Y expone cómo por lo general la acción de los duques constiría en arreglar la Colegiata o elevar la Parroquia mayor a categoría, en promover la construcción de puentes, hacer fuentes y en fundar conventos. Indica que esta última actividad se ejerció con tal grado de dedicación y devoción, que las ciudades ducales españolas, más que centros civiles en honor de un señor, fueron centros religiosos o ciudades-conventos. Su calificación no es la de ciudades ducales sino más bien la de ciudades de patronazgo religioso. Los ejemplos, desde el siglo XV hasta fines del XVI son abundantes: Alba de Tormes, Medinaceli, Pastrana, Guadalajara, Gandía, Fernán Núñez, Osuna, Medina-Sidonia, Bornos, Sanlúcar de Barrameda... En el siglo XVII serán Lerma, Olivares, Loeches... A. Bonet CORREA, El urbanismo en España e Hispanoamérica. Madrid, 199, pp. 26-28.

17 Conviene además recordar que muchas de estas familias además de desplegar fundaciones en el ámbito de sus dominios, también en algún momento de sus trayectoria quisieron establecer alguna nueva comunidad religiosa en alguna de las ciudades más importantes de su entorno, contribuyendo así a esa saturación de cenobios tan visible en ellas. En el caso de Aragón he podido constatar las fundaciones que algunas de las principales familias hicieron en Zaragoza. Pero también en Sevilla, en Córdoba, en Granada, en Valladolid..., y por supuesto en Madrid se levantaron conventos promovidos por la alta nobleza señorial.
}

Hispania Sacra, LXI

123, enero-junio 2009, 51-75, ISSN: 0018-215-X 
tiones conventuales en otros puntos de sus dominios señoriales. Un buen ejemplo puede ser el de los condes de Feria (duques desde 1567), que intensificaron la presencia de familias religiosas en Zafra, pero que levantaron también conventos en otras localidades de las tierras de Badajoz como Salvatierra de los Barros, Barcarrota, Lobón o Villalba de Barros, conventos éstos que serían los únicos que llegaron a verse en sus términos respectivos y que muy probablemente no hubieran acogido ninguno de no ser por el empeño señorial $^{18}$. Y otro ejemplo puede ser el de los duques de Medina Sidonia, responsables en buena medida de la auténtica saturación conventual que en dos siglos se agolpó sobre Sanlúcar de Barameda (Cádiz), pero también fueron los Medina Sidonia autores de otras fundaciones en localidades de importancia bastante más reducida, como Espartinas (Sevilla) o en Conil de la Frontera (Cádiz), poblaciones ambas que no tuvieron ningún convento más a lo largo de su historia.

Pero en el mundo de la nobleza titulada, como es sabido, hay grados, y además de los grandes linajes, fueron muchos también los titulados, menos poderosos, con dominios señoriales de bastante menor entidad, que igualmente se embarcarían en operaciones fundacionales e igualmente en buena parte de los casos los intereses de cariz señorial serían los que orientarían las decisiones. También por lo tanto, desde estos sectores, se contribuiría a la dilatación de la presencia del clero regular en la España Moderna y también a ellos se debería la presencia de claustros en localidades que, sin este empeño por parte de sus señores, quizás no hubieran llegado a albergar una institución de este tipo. Mencionaré sólo algunos casos: el de Navalmoral de Pusa (Toledo), que recibió un convento de capuchinos de manos del marqués de Malpica ya en la fecha tardía de $1732^{19}$ o el de San Lorenzo de la Parrilla (Cuenca), que acogería a los franciscanos por deseo de su señor el marqués de Cañete, por mucho que como reconocía el mismo cronista sobre esta localidad «su vecindad siempre ha sido corta» ${ }^{20}$. De la misma forma llegaron conventos que serían únicos en sus poblaciones a otros núcleos dispersos por distintas zonas de la geografía española como a Puentedeume (La Coruña) por don Fernando de Andrade, conde de Vi-

\footnotetext{
18 Puede seguirse el detalle de la actividad fundacional de muchas de las más importantes familias de la nobleza titulada en A. ATIEnZa LóPEZ, Tiempos de conventos... op. cit., pp. 151 ss.

19 Es éste, por cierto, otro de los conventos que no aparecen en el censo de Floridablanca. Y A. González Caballero asegura que pervivió hasta 1835. A. GonZÁlez CABALlERO, (Coord), Los capuchinos en la Península Ibérica. 400 años de historia (1578-1978), Sevilla, 1985, p. 51. El dato sobre el fundador, en B. de CARrocera, La Provincia de Frailes Menores Capuchinos de Castillla. Vol I: 15751701, Madrid, 1949, pp. 74-76.

${ }^{20}$ P. M. Ortega, Crónica de la Provincia Franciscana de Cartagena. Parte Primera. (Edición facsímil de la impresa en Murcia en 1740). Introducción de J. Meseguer Fernández. Índices y coordinación general de la edición de V. Sánchez Gil, Madrid, 1980, p. 294.
} 
llalba ${ }^{21}$, a Beniparrell (Valencia) por el barón de Beniparrell22, a Gotor (Zaragoza) por los condes de Morata, a Cerralbo (Salamanca) por el marqués de Cerralbo $^{23}$, a Galisteo (Cáceres) por los condes de Osorno ${ }^{24}$, a Vélez-Blanco (Almería) de la mano del marqués de los Vélez ${ }^{25}$, etc.

Intereses particulares también fueron sin duda los de los «nuevos señores», aquellos que habían alcanzado tal condición bien al calor de las ventas de jurisdicciones que tuvieron lugar bajo los Austrias o bien por compra de señorío a particulares. Nos referimos tanto a individuos que en ocasiones formaban parte ya de familias reconocidas como a individuos de escalones más secundarios y que no pararon hasta establecer un convento en las localidades señoriales que acababan de adquirir ${ }^{26}$. Era la forma de certificar el encumbramiento social, pero también era una vía de prestigiar la localidad y realzar la entidad del nuevo señorío. Ellos o sus sucesores hicieron que estas poblaciones, muchas de ellas desprovistas de conventos hasta el momento, vieran entonces como en sus términos comenzaba la edificación de uno o dos conventos. Y no estamos hablando ni de localidades especialmente prósperas ni de tiempos especialmente florecientes. El empeño de estos señores y sus intereses específicos de cara a sus nuevos señoríos desviaría la tendencia de las órdenes religiosas a instalarse en los enclaves más populosos y opulentos. Así llegaron conventos a localidades como Paracuellos del Jarama (Madrid), Mora (Toledo), Velada (Toledo), Auñón (Guadalajara), Valdepeñas (Ciudad Real) ${ }^{27}$, Baltanás (Palencia) ${ }^{28}$, Grajal de Campos (León) ${ }^{29}$, Uceda (Guadalaja-

${ }^{21}$ B. Estrada Robles, Los agustinos ermitaños en España hasta el siglo XIX, Madrid, 1988, p. 204

22 B. Velasco Bayón, Historia del Carmelo español. Textus et studia historica carmelitana, XVIII. Vol. II: Provincias de Cataluña, Aragón y Valencia, 1563-1835, Roma, 1992, p. 360.

${ }^{23}$ AHN, Consejos, leg. 50815.

${ }^{24}$ AHN, Nobleza, Fernán Nuñez, C. 453.

${ }^{25} \mathrm{M}^{\mathrm{a}} \mathrm{R}$. TORRES FERNÁNDEZ, «Los conventos franciscanos del Obispado de Almería (1489-1855)», en I Curso de Verano. El franciscanismo en Andalucía, Córdoba, 1997, pp. 281-298.

${ }^{26} \mathrm{~J}$. C. Vizuete Mendoza ya mostró algunos ejemplos entre fundadores de su ámbito de estudio, individuos que habían adquirido -ellos o sus sucesores- el señorío de las localidades en que instalaron sus conventos. Los ejemplos se referían a Melchor de Herrera, Nicolás Fernández Polo, Doña Luisa de la Cerda, Francisco de Rojas, los duques de Pastrana y Álvaro Bazán. J.C. Vizuete MendozA, «Los regulares en el territorio castellano de las Órdenes Militares (siglos XVI-XVIII)», en J. LóPEZ-SALAZAR, (Coord), Las Órdenes Militares en la Península Ibérica, vol II, Edad Moderna, Cuenca, 2000, pp. 2135-2159. Por mi parte, también he podido ampliar la nómina de ejemplos. A. ATIENZA LóPEZ, Tiempos de conventos...op. cit., pp. 207 ss.

${ }^{27}$ Ejemplos constatados por J. C. Vizuete en el trabajo citado arriba.

28 AHN, Consejos, leg. 50815.

${ }^{29}$ Fr. J de Santa María, Chronica de la Provincia de San Joseph de los Descalzos de la Orden de los Menores de N. Seraphico Padre San Francisco y de las Provincias y Custodias Descalzas, que della han salido y son sus hijas. Madrid, 1625, pp. 340-341 de la parte $2^{\circ}$.

Hispania Sacra, LXI

123, enero-junio 2009, 51-75, ISSN: 0018-215-X 
ra $)^{30}$, Santa Cruz de la Sierra (Cáceres) ${ }^{31}$, Boadilla del Monte (Madrid) ${ }^{32}$..., localidades también que llegarían a finales del Antiguo Régimen con esta única presencia conventual.

Intereses particulares fueron también los de los flamantes nuevos titulados nobiliarios que quisieron enaltecer el recién conseguido título con una fundación conventual, como casi todos los nobles que se preciaran. Pero intereses particulares fueron también los de aquellos que en pleno proceso de ascenso social y en plena carrera para la consecución de un título nobiliario consideraron que la condición de «fundador de un convento» acreditaba sus deseos y podía impulsar sus aspiraciones. Así, tanto recién titulados como aspirantes al título protagonizaron de forma notable la ampliación del tejido conventual de la España Moderna.

Ambos fenómenos -procesos de ennoblecimiento y de proliferación conventual- estuvieron muy vinculados. La configuración conventual de la España Moderna debió mucho a la «titulomanía», a la ambición de títulos nobiliarios y a las aspiraciones de ascenso y reconocimiento social. No me detendré demasiado en ello dado que he analizado esta cuestión en otros estudios recientes ${ }^{33}$. No obstante, sí insistiré en la perspectiva que estamos desarrollando ahora: fueron los intereses específicos y privativos de los nuevos titulados y de aquellos que veían factible lograrlo los que también actuaron como motor de la expansión de las comunidades religiosas y los que determinaron su localización ${ }^{34}$. También en estos casos es factible ver cómo se abrían conventos en localidades

${ }^{30}$ AHN, Nobleza, Frías, C. 954. Y, A. JimÉnEz EstrellA, «El precio de las almena: ventas de alcaidías de fortalezas reales en época de los Austrias», Revista de Historia Moderna. Univ. de Alicante, 22 (2004), pp. 143-172.

${ }^{31}$ La fundación del convento, en A. Martínez Cuesta, Historia de los Agustinos Recoletos. Vol I. Desde los orígenes hasta el siglo XIX, Madrid, 1995, p. 271. La referencia a la compra del lugar por don Juan de Chaves y Mendoza, en J. FAYARD, Los miembros del Consejo de Castilla (1621-1746). Madrid, 1982, p. 508.

32 En este caso la consecunción del señorío por don José González de Uzqueta se produjo por compra a un particular, el marqués de Belmonte. La fundación en 1670 del convento de las carmelitas descalzas en Boadilla del Monte se realizaría por deseo de don Juan González de Uzqueta, su hijo, aunque la ejecución correspondería a su mujer, ya viuda. J. FAYARD, Los miembros del Consejo de Castilla..., op. cit., pp. 326 y 487.

${ }^{33} \mathrm{He}$ anticipado estos planteamientos en las comunicaciones siguientes: A. ATIENZA LóPEZ, «Fundaciones y patronatos conventuales y ascenso social en la España de los Austrias» y «Nuevos títulos y nuevos conventos en la España de los Austrias», presentadas en el Congreso Internacional «Las elites en la época moderna. La monarquía española», celebrado en la Universidad de Córdoba en octubre de 2006. Sus actas están en prensa.

${ }^{34}$ Algunos de los casos ya expuestos en relación con la adquisición de jurisdicciones señoriales se vieron también acompañados de la consecución de títulos. Además también en estos casos vuelve a ser visible la orientación señorial de estas fundaciones conventuales, ahora en las localidades que prestaban su nombre a los títulos recién conseguidos. 
que no contaban con ninguna presencia de órdenes religiosas ni tampoco volverían a recibir ningún nuevo cenobio en el transcurso de las centurias modernas. Así sucedió en Valdefuentes (Cáceres) ${ }^{35}$, en Ardales (Málaga) ${ }^{36}$, en Luque ${ }^{37}$, en Valdunquillo (Vallodolid) ${ }^{38}$, en Mancera de Abajo (Salamanca) ${ }^{39}$, en Barajas (Madrid) ${ }^{40}$, en Costeán (Huesca) ${ }^{41}$, en Torre de Esteban Hambrán (Toledo) ${ }^{42}$, en Elda (Alicante) ${ }^{43}$, en Távara (Zamora) ${ }^{44}$, en Las Navas del Marqués (Ávila) ${ }^{45} \mathrm{o}$ en Alcañices (Zamora) ${ }^{46}$, entre otros.

Intereses particulares fueron también los de aquellos eclesiásticos más o menos opulentos, que se empeñaron en inaugurar un claustro en sus localidades

${ }^{35}$ Allí se estableció un convento de agustinos recoletos, por don Alonso de Alencastro, marqués de Valdefuentes. A. MARTínez CuESTA, Historia de los Agustinos Recoletos..., op . cit., pp. 272 ss.

${ }^{36}$ A. de Valencina, Reseña histórica de la Provincia capuchina de Andalucía y varones ilustres en ciencia y virtud que han florecido en ella desde su fundación hasta el presente, Sevilla, 1906, tomo II, pp. 39 ss.

${ }^{37}$ Se abrió el convento de agustinos recoletos por el I conde de Luque, don Salvador Egas Venegas. F. FERNÁNDEZ DE BÉTHENCOURT, Historia genealógica y heráldica de la monarquía española. Casa Real y Grandes de España, Sevilla, 2003, tomo VII, p. 263.

38 Un convento éste, de mercedarios descalzos, de los que no aparecen en el censo de Floridablanca. AHN, Clero, Libro 16651. Y, Fr. P de SAN CECILIO, Annales del Orden de Descalzos de Nuestra Señora de la Merced Redempcion de Cautivos Christianos. Parte Segunda, Barcelona, 1669, pp. 618 ss.

39 Un convento de mínimos, promovido por quien después sería el I marqués de Mancera. L. de Montoya, Crónica general de la Orden de los Mínimos de San Francisco de Paula, Madrid, 1619.

40 Allí llegaron los franciscanos descalzos de la mano de don Francisco Zapata, conde de Barajas. AHN, Fernán Nuñez, C. 747. También, Fr. J de SAnTA María, Chronica de la Provincia de San Joseph de los Descalzos..., op. cit., p. 580.

41 Se establecieron los agustinos calzados, por iniciativa de los progenitores de los titulados como marqueses de Coscojuela. A. Claver Ferrer, Noticias historiales del Conbento (sic) de Nuestro Padre San Augustín de Çaragoza y de los demás del Reyno de Aragón. Zaragoza, 1695. (Edición de Jose Luis Santiago, Revista Agustiniana. Madrid, 2000), pp. 213 ss.

42 Un convento de franciscanos descalzos, por quienes tendrían el título de marqueses de la villa, según se certifica en las Descripciones del Cardenal Lorenzana. Puede verse, J. PORRES, H. RodríGUEZ y R. SÁnchez, Descripciones del Cardenal Lorenzana (Archivo Diocesano de Toledo), Toledo, 1986, p. 581 .

43 Por los condes de Elda, un convento de franciscanos. AHN. Consejos, leg. 50840: V. MARTíneZ Colomer, Historia de la Provincia de Valencia de la Regular Observancia de San Francisco. Tomo Primero. Manuscrito, siglo XVIII, fol 171.

44 Se estableció aquí en 1559 un monasterio de jerónimos fundado por el I marqués de Távara, título que había recaido en el nieto de los III condes de Benavente, don Bernardino Pimentel, aunque posteriormente la orden abandonaría el establecimiento, y posteriormente sería ocupado por los dominicos. Fr. J. de SigüEnZA, Historia de la Orden de San Jerónimo, Salamanca, 2000. Es la edición de la obra de fray José Sigüenza de 1600-1605, p. 176.

45 Se instalaron los dominicos, con el apoyo de los primeros marqueses de Las Navas, según se contempla en las referencias dadas por M. DE LOS Hoyos, Registro Historial de nuestra Provincia, Madrid, 1968, tomo I, p. 213.

46 Un convento de franciscanos observantes que hizo edificar hacia 1542 quien unos años después sería titulado como I marqués de Alcañices. Anónimo, Crónica de la Provincia Franciscana de Santiago, 1214-1614, Introducción de M. de Castro, Madrid, 1971.

Hispania Sacra, LXI

123, enero-junio 2009, 51-75, ISSN: 0018-215-X 
natales. En una manifestación clara de la importantísima vinculación que los miembros del clero secular, y en particular de sus estratos más elevados, mantuvieron con sus respectivas familias, canónigos, arcedianos y otros representantes de la clerecía secular que se decidieron a promover una fundación conventual lo hicieron impulsados por consideraciones muy particulares, que les llevaron a elegir con mucha frecuencia sus lugares natales como enclave para la nueva comunidad religiosa que promovían y que debía convertirse en una pieza de apoyo y soporte a las estrategias y a los intereses de su grupo familiar de pertenencia. Y así es como llegaron conventos, que serían únicos en sus términos, a lugares como Villasana de Mena (Burgos), de la mano de un canónigo hispalense que había nacido en esa localidad burgalesa ${ }^{47}$, o a Valencia del Ventoso (Badajoz), por un cura de Yepes (Toledo) y natural del lugar donde estableció una comunidad de franciscanas concepcionistas ${ }^{48}$, o Bonilla de la Sierra (Ávila), lugar en la que había nacido y quiso fundar el deán de Calahorra, don Gaspar Ortuño ${ }^{49}$, o también a Rute (Córdoba), favorecido por un vicario de la iglesia sevillana, nacido allíso.

Pero también las iniciativas fundacionales de obispos y arzobispos respondieron muchas veces a los intereses de las políticas familiares. Es cierto que algunas de las fundaciones promovidas por las altas jerarquías del clero secular estuvieron alentadas por motivaciones diocesanas y consideraciones de tipo pastoral, pero no es menos cierto que muchas otras se debieron a impulsos mucho más personales. Los intereses y las filiaciones familiares constituyeron también para estos sectores del clero secular un muy importante motor fundacional. También es posible ver a estos insignes prelados levantando conventos en sus localidades natales o, en su defecto, en aquellas otras poblaciones en las que sus familias de pertenencia desplegaban sus redes de poder. En ocasiones podía tratarse de localidades de una cierta importancia, que albergaban o lo haría posteriormente algún otro convento ${ }^{51}$, pero también localidades de menor entidad, pero muy vinculadas al prelado fundador, se vieron ampliadas con un

47 J. M. López CuÉtARA, «La Orden de la Inmaculada Concepción en Burgos, siglo XVI», en I Congreso Internacional del Monacato femenino en España, Portugal y América, 1492-1992, t. II, León, 1993, pp. 309-320.

48 M. de CASTRO, «Los monasterios de concepcionistas franciscanas en España», Archivo IberoAmericano, 203-204 (1991), pp. 411-477.

49 Un convento éste, de franciscanos descalzos, que tampoco aparece en el censo de Floridablanca. AHN, Consejos, leg. 50815. También, Fr. J de SAnTA María, Chronica de la Provincia de San Joseph de los Descalzos..., op. cit., p. 331.

50 A. de TorRes, Crónica de la Provincia franciscana de Granada, Reproducción de la edición del año 1683. Edición preparada por Rafael Mota Murillo, Madrid, 1983, tomo I, p. 148.

51 Sería, entre otros, el caso de la conocida fundación del convento de franciscanos en Talavera de la Reina (Toledo) impulsada a fines del XV por el primer arzobispo de Granada, fray Hernando de Talavera. 
cenobio. Sería el caso de el caso de Casalarreina (La Rioja), donde el convento de dominicas que se abrió respondería a la intención fundacional de don Juan Fernández de Velasco, obispo de Calahorra, y miembro de la familia de los duques de Frías-condes de Haro ${ }^{52}$, o el caso de Cangas de Narcea, en Asturias, donde se abriría hacia 1658 un convento de dominicas promovido por don Juan Queipo de Llano, natural del lugar y obispo de Pamplona y de Jaén ${ }^{53}$, o también el de San Martín de Don (Burgos), donde había nacido don Juan Ochoa de Salazar, que ocuparía el obispado de Plasencia, y donde establecería una comunidad de clarisas ${ }^{54}$.

Y es que, ciertamente, los criterios de conveniencia o inconveniencia, los intereses de carácter general, la atención a la utilidad y el provecho colectivo normalmente quedaron relegados a un segundo plano. Como venimos viendo, no fueron pocos los conventos que se erigieron en localidades que, posiblemente por sí mismas, no hubieran justificado la presencia de una comunidad religiosa, pero el deseo de los fundadores y sus consideraciones particulares se pusieron por delante. Y así, como hemos visto, el día que el obispo don Juan Ochoa de Salazar quiso fundar en aquella aldea burgalesa en el valle de Tovalina llamada San Martín del Don que le había visto nacer, lo hizo: un convento de franciscanas clarisas, en el que podrían entrar sin dote sus parientas, se fundaba en 1593 y perviviría hasta finales del Antiguo Régimen.

Intereses particulares fueron también las de aquellos indianos enriquecidos que quisieron invertir sus relucientes fortunas en dotar con un convento su lugar de origen. Allí debían plasmarse los éxitos y el volumen de los caudales conseguidos y allí debían recogerse las rentas del prestigio y del honor que cualquier fundación conventual, masculina o femenina, acarreaba por sí misma. También en estas fundaciones quedaban enredadas las filiaciones y las querencias familiares. Desde América se hacían mandas que debían beneficiar a sus familiares, pero también es visible el afecto a esa «patria chica» que se había abandonado y el deseo de favorecerla ${ }^{55}$. Y, junto a las iniciativas fundacionales ordenadas desde tierras americanas, también se emprendieron otras en el momento del regreso a la tierra natal. En la aspiración al reconocimiento social se inmovilizaron muchas de las fortunas obtenidas en Indias en forma de obras piadosas de todo

\footnotetext{
52 Sería su hermano, el duque de Frías -conde de Haro-, quien al fallecer el prelado, llevaría a efecto la obra, AHN, Nobleza, Frías, C. 416.

${ }_{53}$ Moriría antes de ver ejecutado su deseo, y dejaría a su hermano encargado de proseguir la operación fundacional. M. de los Hoyos, Registro Historial de nuestra Provincia..., op. cit., tomo II, pp. 154 ss.

${ }^{54}$ G. González Dávila, Teatro eclesiástico de las Iglesias Metropolitanas, y Catedrales de los Reynos de las Dos Castillas...Tomo II: Contiene las Iglesias de Sevilla, Palencia, Ávila, Zamora, Coria, Calahorra y Palencia, Madrid, 1647.

55 No era infrecuente que, en las condiciones que planteaban para las fundaciones femeninas, estos emigrados hicieran constar que, tras las mujeres de su entorno familiar, se vieran beneficiadas con reserva de plazas en el convento, las mujeres naturales de la localidad o del entorno. 
tipo. La fundación de un convento, no hay duda, resultaba una operación de gran trascendencia, y por esta vía se levantaría conventos en localidades como Los Hoyos (Cáceres) ${ }^{56}$, Bárcena de Campos (Palencia) ${ }^{57}$, Campo de Criptana (Ciudad Real) ${ }^{58}$, Puertollano (Ciudad Real) ${ }^{59} \ldots$, poblaciones que seguramente no hubieran contado con ellos -su único convento- de no haber mediado el impulso de estos naturales emigrados a Indias y su empeño particular ${ }^{60}$.

Intereses particulares fueron también los de aquellas viudas con más o menos recursos que decidieron vivir su viudedad entre las paredes de un convento y acabar sus días en un claustro de su fundación, levantado si era posible en el mismo lugar en el que vivieron. En algunos casos, incluso, parece que la fundación tuvo además otro componente personal añadido, al ocupar sus fundadoras los cargos de priora o abadesa de la nueva institución, como sucedió en el convento de concepcionistas que hacia 1651 se fundaba en Fuensaldaña (Valladolid) por doña Mariana de Menchaca y Vázquez, madre del conde de Fuensaldaña y monja que era ya de la recoletas de Zamora, que pasaría a ser abadesa de la nueva fundación 61 .

Y, por último, ¿qué se puede afirmar sobre el comportamiento de los concejos? En otro lugar ya he podido poner de manifiesto cómo en el análisis de las fundaciones promovidas por las corporaciones concejiles en la España del Antiguo Régimen, y al lado de iniciativas municipales que se tomaron en localidades populosas y destacadas que acogieron un número destacado de conventos, uno de los aspectos que sobre todo llama la atención es la cantidad de poblacio-

56 Un convento de franciscanos, que quiso levantar Pablos Pérez, que al parecer habría participado en la conquista del Perú junto a los Pizarro y a quien Felipe II le reconocería categoría noble. Fr. J de Santa CRuz, Crónica de la Provincia Franciscana de San Miguel. Parte primera, Reproducción facsimilar de la edición de 1671. Introducción e Índices de H. Zamora Jambrina, Madrid, 1989, pp. 426427.

${ }^{57}$ Una comunidad de basilios, patrocinada hacia 1595 por García Manrique de la Vega y su esposa Leonor de Salazar, un matrimonio de indianos palentinos. M. REvUELTA GonZÁLEZ, «Orígen, ocaso y renovación de los conventos palentinos», Publicaciones de la Institución Tello Téllez de Meneses, 63 (1992), pp. 47-84.

58 Un convento de carmelitas descalzos, cuya fundación se vería beneficiada por el apoyo del indiano Andrés Velázquez Arias, que dejó en su testamento seis mil ducados para que en su tierra se levantara un convento de la mencionada orden. Fr. J. de SANTA TERESA, Reforma de los Descalzos de Nuestra Señora del Carmen de la primitiva observancia hecha por Santa Teresa de Jesús en la antiquissima religión fundada por el gran profeta Elías, t. III, Madrid, 1683, p. 157.

${ }_{59}$ Un convento de franciscanos descalzos, ordenado y financiado por el negociante indiano Juan Caballero París. J. J. Barranquero: Conventos de la provincia de Ciudad Real, Ciudad Real, 2003, p. 132.

${ }^{60}$ Quizás sí en el caso de Campo de Criptana, pues se trató de un convento cuya fundación llevaba intentando realizar el concejo de la localidad.

${ }^{61}$ M. de CASTRO, «Los monasterios de concepcionistas franciscanas en España», Archivo IberoAmericano, 203-204 (1991), pp. 411-477. 
nes de bastante menor entidad cuyas instituciones municipales reclamaron tener un convento y lo consiguieron ${ }^{62}$. He podido contabilizar hasta cincuenta y seis localidades cuya único convento fue debido a la movilización de las autoridades locales para conseguirlo, corporaciones que pondrían así su contribución particular a esa amplitud de la presencia del clero regular en la España Moderna y a esa dispersión que la geografía conventual terminó por presentar, al lado de las grandes y puntuales aglomeraciones de claustros.

Resulta quizás más difícil documentar hasta qué punto fueron intereses particulares los estuvieron detrás de las iniciativas tomadas por tantos concejos que fueron promotores de fundaciones conventuales en los términos de sus respectivas localidades. Pero en ciertos casos sí es posible detectar comportamientos muy específicos. De intereses particulares pueden calificarse los de aquellas corporaciones que se planteaban la necesidad de un convento de monjas donde colocar honrosamente a sus hijas. Así, el convento de franciscanas clarisas de Báguena sería obra de la propia Comunidad de Daroca. V. Blasco de Lanuza explica como en sus reuniones «se habian hecho pláticas de la conveniencia de un Convento de monjas para las hijas de hombres principales della», nombrándose una junta de seis personas para llevar adelante la empresa y eligiéndose para ello el lugar de Báguena. Dado que la iniciativa la tomaba la Comunidad, se repartiría el coste de la obra entre los lugares que la integraban. El convento sería una realidad en $1612^{63}$. Sólo cinco años después otra claustro de monjas se establecería en Miedes (Zaragoza). El mismo Blasco de Lanuza relatará cómo «a imitación del convento de Báguena», quiso fundar también la Comunidad de Calatayud un convento de monjas y lo fijó en aquella localidad ${ }^{64}$. Y es que, no hay que descartar que la emulación y la competencia latiera en el seno de estas corporaciones supralocales, lo mismo que en el seno de los municipios, y actuara también como elemento de inducción de las decisiones orientadas a emprender una fundación en la propia localidad o en cualquiera de las que integraban la comunidad, como hemos visto.

Con carácter general la presencia de un convento otorgaba un importante grado de reputación y de prestigio a la villa que lo acogía. Sí cabe recordar cómo el cronista García Alcaraz explicaba la pretensión de fundar un convento que movilizó al concejo de Mazarrón (Murcia): «abrasó a la villa en vivísimos deseos de añadirse blasones, solicitando Fundación» 65 , y con esta elocuente y

62 A. Atienza López, Tiempos de conventos... op. cit., pp. 387 ss.

${ }^{63}$ V. Blasco dE LANUZA, Historias eclesiásticas y seculares de Aragón en que se continúan los Annales de Zurita, desde el año 1556, al de 1618, Zaragoza, 1622. (Edición facsimilar de Zaragoza, 1998), p. 539.

64 Ibid., p. 541.

65 Fr. G García Alcaraz, Segunda Parte de las Chronicas de la Santa Provincia de San Pedro de Alcántara de religiosos menores descalzos de las más estrecha observan cia de N.P.S. Francisco en los Reynos de Granada y Murcia, escrita por-, Murcia, 1761, p. 178.

Hispania Sacra, LXI

123, enero-junio 2009, 51-75, ISSN: 0018-215-X 
plástica mención de sumarse «blasones» reflejaba bien la carga de honor y lustre que acompañaba a los establecimientos conventuales y que aportaba a sus poblaciones. Evidentemente, las oligarquías y las élites locales eran conscientes de ello y del beneficio político en forma de legitimación y de aprobación social y en forma de consenso y orgullo local que les proporcionaba. Por ello también este efecto actuaría como factor que impulsó la competencia y la emulación entre los pueblos, creando una situación en la que muchas villas y núcleos de población, independientemente de su entidad demográfica y de sus necesidades objetivas de atención espiritual y pastoral acariciaban la idea de tener su propio convento y presionaron sobre las órdenes religiosas para conseguirlo. Esto no significa, desde luego, que muchas otras corporaciones no hicieran llamamientos de fundación a las órdenes religiosas buscando fundamentalmente mejorar y completar por esta vía la atención religiosa de sus feligreses.

\section{TENDENCIAS QUE MARCARON ALGUNAS ÓRDENES NUEVAS Y REFORMADAS}

Este mismo océano de intereses particulares que venimos punteando nos obliga a plantear otras cuestiones importantes y lógicas: ¿en qué quedaron las consideraciones de las órdenes religiosas?, ¿hasta qué punto fueron al socaire de las demandas y reclamaciones de fundación que les llegaban? O, por el contrario, ¿hasta qué punto desarrollaron políticas propias y marcaron las líneas de actuación y asentamiento que consideraron más convenientes?

Evidentemente no todas las llamadas y las demandas que particulares laicos, eclesiásticos, concejos... deseosos de fundar hicieron a las órdenes religiosas para que se establecieran allí donde se les reclamaba fueron respondidas.

Por supuesto, no puede negarse que en ocasiones las órdenes religiosas rechazaron ofertas de fundación que les llegaban. Sin embargo, al menos en las fases iniciales de la expansión y en los procesos de formación de nuevas custodias y/o provincias, las nuevas órdenes no debieron declinar muchas de las proposiciones que les hacían, porque del número de conventos que regentaran dependía la formalización de la demarcación prevista y, en definitiva, dependía de ello su entidad institucional. Como hemos podido ver claramente en el caso de los capuchinos, las ansias de estar presentes, la aspiración de consolidarse y el empuje de la formación de provincias fueron de tal magnitud que se hicieron muchas fundaciones apresuradas, como más tarde reconocerían las propias jerarquías de la orden ${ }^{66}$. Por lo demás, también cabe pensar que no siempre debió

${ }^{66}$ A. Atienza López, Tiempos de conventos... op. cit., pp. 419 ss. Sobre los capuchinos, son imprescindibles los trabajos de T. de AzConA, «La formación de la provincia de capuchinos de Navarra y Cantabria en el siglo XVII», Príncipe de Viana. Anejo, pp. 25-34. «Protohistoria de los Capuchinos en España», Collectanea Franciscana, 68 (1998), pp. 63-145. «Los franciscanos capuchinos en la Penín- 
resultar sencillo, ni muchas veces recomendable, rehusar una oferta si quien la hacía era especialmente poderoso, por mucho que el enclave en el que debía abrirse el nuevo claustro no conviniera ni gustara a la orden religiosa. Tampoco parecía conveniente renunciar a una buena dotación aunque la localidad de destino no fuera la más atractiva.

Tampoco se puede negar que las órdenes religiosas articularon y plantearon estrategias para conseguir que particulares y concejos les hicieran llegar súplicas de fundación en aquellos lugares que interesaban a la propia orden, aunque esto no impide reconocer que realmente fueron muchas las ocasiones en las que el primer paso no lo daba la familia religiosa. Es posible que en muchos resultados fundacionales coincidieran algunos de los intereses particulares mencionados arriba con los propios de las órdenes religiosas, incluso cabe pensar que la acción y la intervención de éstas pudiera estimular expectativas personales y decantar decisiones fundacionales. No es fácil, como es lógico, determinar el nivel de su intervención.

Lo que sí puede considerarse un hecho probado, como hemos visto, es que también se abrieron conventos en lugares de escaso peso, en poblaciones de entidad más modesta, en pueblos no especialmente opulentos. Y es un hecho además que una parte de estas fundaciones quedó vinculada de forma especial a algunas órdenes religiosas concretas. Por esto, apuntaba más arriba que en la explicación de esta geografía conventual desplegada por un número importante de poblaciones había que considerar también las tendencias que pudieron marcar algunas de las órdenes nuevas y reformadas, de la misma manera que debemos contar también con la incidencia que tuvieron las campañas de reprobación y oposición emprendidas por las órdenes más antiguas ya asentadas.

Los estudios realizados sobre la dinámica de órdenes concretas nos pueden permitir arrojar algo más de luz en torno a la determinación de los factores que intervinieron en las resoluciones de establecer convento en un lugar determinado.

La difusión de los franciscanos descalzos durante los siglos XVI y XVII, por ejemplo, fue realmente extraordinaria, y en esa medida, significativa. Empezamos a saber, por ejemplo, cómo en los primeros momentos los establecimientos de la descalcez franciscana tendieron en muchas ocasiones a esquivar los núcleos de los franciscanos observantes ${ }^{67}$ y a localizarse en enclaves situados en una posición periférica respecto a ellos. La protección dispensada a la observancia por parte de las jerarquías eclesiásticas y la monarquía y el esfuerzo por contener la expansión descalza por parte de los franciscanos observantes

sula Ibérica en los siglos XVI-XVII», en Ma . M. GRAÑa CID, (Ed), El franciscanismo en la Península Ibérica. Balance y perspectivas, Barcelona, 2005, pp. 297-318. Y el trabajo reciente, La fundación de los capuchinos en Zaragoza (1598-1607), Zaragoza, 2005.

${ }^{67}$ Muchos de los cuales, por su parte, también se localizaban en poblaciones de no gran peso.

Hispania Sacra, LXI

123, enero-junio 2009, 51-75, ISSN: 0018-215-X 
no serían ajenos a esta orientación de las fundaciones ${ }^{68}$. El florecimiento inicial de claustros en territorio extremeño se ha interpretado en parte función de estos factores. A. Rodríguez Sánchez, en un trabajo poco conocido sobre la expansión franciscana en Extremadura, ponía de manifiesto ya cómo la opción extremeña para los descalzos «significa un alejamiento práctico de los centros de control político y religioso, pues tanto la geografía como la economía marcan a Extremadura como fronteriza y periférica ${ }^{69}$. Más aún, un mapa de los conventos de la descalcez en Extremadura anteriores a la muerte de San Pedro de Alcántara en $1562^{70}$ pone de manifiesto cómo una buena parte de los establecimientos se situaron además en zona periférica, en las proximidades de los límites con Portugal.

Los recelos de los franciscanos observantes y la combatividad frente a la expansión descalza también debió ser bastante notable en el territorio murciano y esta circunstancia debió intervenir asimismo en la orientación de las fundaciones de los franciscanos descalzos. De forma expresa se reconocía en la Provisión real que, a instancia de los observantes, se enviaba en 1599 a la justicia de la ciudad de Murcia para que no consintieran la fundación de monasterios franciscanos en la provincia de Cartagena ${ }^{71}$. Se decía en ella que los franciscanos descalzos «avian procurado y procuraban fundar los dichos monasterios en lugares pequeños adonde les parecía tendrían menos contradiçion y adonde no se tenia noticia de las proiviciones de nuestras leies reales y generales estatutos de la dicha horden...», de modo que, efectivamente, también aquí parece que puede afirmarse que los descalzos se inclinaron a buscar su acomodo en localidades de menor entidad, evitando así las campañas de acoso orquestadas por los poderosos franciscanos observantes y procurando sortear la posible persecución de la justicia real.

Junto a estos factores de cariz más político, tampoco pueden omitirse otros elementos a la hora de explicar en toda su complejidad la caracterización de la

\footnotetext{
68 Sobre las sucesivas reformas en el seno del franciscanismo se ha escrito mucho. Puede verse un buen resumen en J. GARCÍA ORO, «Reforma y reformas en la familia franciscana del Renacimiento. Cuadro histórico del tema», en $\mathrm{M}^{\mathrm{a}}$ M. GRAÑA CID (Ed), El franciscanismo en la Península Ibérica. Balance y perspectivas. Barcelona, 2005, pp. 235-254. Así, como su ya clásico, «Conventualismo y observancia. La reforma de las órdenes religiosas en los siglos XV y XVI». En R. García ViLlosLadA (Dir.), Historia de la Iglesia en España. B.A.C. Madrid, 1980. Vol. III-1. Pp. 211-350.

${ }^{69}$ A. RodríguEZ SÁNCHEZ, «Los franciscanos en Extremadura. Expansión religiosa y social. Siglos XVI al XVIII», en Congreso «Franciscanos Extremeños en el Nuevo Mundo». Monasterio de Sta $\mathrm{M}^{\mathrm{a}}$ de Guadalupe, 1986, pp. 129-150. El subrayado corresponde al original.

70 Puede verse en H. Amez Prieto, La Provincia de San Gabriel de la Descalcez franciscana extremeña. Arganda del Rey, 1999. p. 53.

${ }^{71}$ El texto de la provisión lo publican y transcriben íntegro J. García Oro y Ma J. PORTELA SiLva, «Los frailes descalzos. La nueva reforma del Barroco», en Archivo Ibero-Americano, 60 (2000), pp. 511-586. El texto, en pp. 537-539.
} 
geografía conventual moderna. No podemos olvidar, por supuesto, que la reforma descalza se inició buscando enclaves apartados y los lugares pobres también como parte de sus señas de identidad específicas. El mismo A. Rodríguez aseguraba en el caso de Extremadura que fueron «precisamente núcleos donde se establecen los descalzos los que mayor índice de pobreza poseen», como Belvís de Monroy, Arroyo del Puerco, Brozas, Robledillo y Gata ${ }^{72}$.

Ciertamente, no resulta fácil evaluar los niveles de pobreza en los marcos locales con carácter general y supera con creces nuestras posibilidades presentar un cuadro que relacione ambas variables: fundaciones y niveles de pobreza locales, pero sí es posible valorar otro tipo de indicios que nos orientan en la misma dirección. En 1573 los franciscanos descalzos fundaban convento en la localidad segoviana Martín Muñoz de las Posadas. El cronista asegura que «hizose de limosnas particulares casi milagrosamente porque cuando se comenzó no había mas de cien reales solos para la obra, sin certidumbre ni aún esperanza de quien diesse mas por ser el Pueblo muy pobre.... ${ }^{73}$. ¿Qué puede decirse de otras localidades del interior peninsular, castellanas, manchegas, extremeñas.. que desde las últimas décadas del siglo XVI y en la fases más duras de la siguiente centuria fueron acogiendo alguna comunidad religiosa? La riqueza no abundaba precisamente en esas tierras por aquellos tiempos. Y no fueron sólo uno o dos los conventos que se levantaron con el esfuerzo de los vecinos y con las limosnas anónimas de decenas de fieles.

No obstante, y aunque nos hemos centrado en el ejemplo de los franciscanos descalzos, sí conviene subrayar que la tendencia a establecer fundaciones en lugares de menor peso y entidad estuvo presente en general en el conjunto de la familia franciscana. Parece claro que fueron las distintas ramas del franciscanismo, incluidos también los capuchinos, quienes proporcionalmente más establecimientos tuvieron en localidades en las que su convento fue el único, destacándose también el conjunto de los franciscanos -y no tanto en este caso los capuchinos- por ser quienes menor presencia proporcional tuvieron en aquellas villas y ciudades donde proliferaron y se concentraron mayor número de conventos. Por el contrario, merece la pena también llamar la atención sobre el muy distinto perfil presentado por la Compañía de Jesús, con muy pocos colegios abiertos en localidades que no tuvieron otra presencia regular e incluso también en enclaves donde sólo se habría abierto otro convento más; un panora-

72 A. Rodríguez SÁNCHEZ, «Los franciscanos en Extremadura...», op. cit.

${ }^{73}$ B.N. Ms. 1173. Crónica de la Provincia de San Joseph de la Religión de San Francisco desde su fundación hasta el año de 1584. Fol. 32. También, el cronista Santa María indicaría que se hizo «toda la casa de limosnas de los naturales de villa y tierra, que con mucha devoción acudían a trabajar a la obra...». Fr. J de SAnTA María, Chronica de la Provincia de San Joseph de los Descalzos de la Orden de los Menores de N. Seraphico Padre San Francisco y de las Provincias y Custodias Descalzas, que della han salido y son sus hijas. Madrid, 1625. P. 369.

Hispania Sacra, LXI

123, enero-junio 2009, 51-75, ISSN: 0018-215-X 
ma, el de la distribución geográfica de los jesuitas, en el que predominaron las ciudades de tipo medio y grande y en el que, por el contrario, los pequeños pueblos tuvieron una presencia puramente testimonial.

Algunas otras órdenes, por su parte, debatirían internamente la dirección de su política de establecimientos, abriéndose discrepancias en ello. Así, sabemos, cómo entre los carmelitas calzados una de las corrientes de opinión defendía «que el bien de la Orden consistía en multiplicar los conventos en pueblos pequeños de España y dejarnos de lo demás», mientras que otra, en la que figuraba el padre Gracián, prefería un número más reducido de conventos, en ciudades importantes, con preferencia de las universitarias ${ }^{74}$. A la postre, el resultado de su presencia, ya a fines del Antiguo Régimen podría ser bien un reflejo de la combinación de ambas posturas.

Las distintas características y peculiaridades, los diferentes ideales y objetivos de las órdenes se manifestaron por lo tanto en las orientaciones geográficas de sus fundaciones, en las consideraciones que hicieron en torno al establecimiento de sus respectivas redes conventuales, de la misma manera que también sus correspondientes particularidades institucionales incidieron en sus procesos de difusión. La expansión de las distintas órdenes religiosas se verificó con ritmos y rasgos diferentes. El estudio particular por órdenes exige un trabajo monográfico con más detalle que el que es posible en estas páginas, de manera que lo que he planteado en las líneas anteriores es un mero avance y una somera aproximación que requiere un desarrollo más amplio y un examen más detenido. En cualquier caso, sí parece claro que no cabe generalizar en exceso la idea de la propensión a una orientación urbana en todas las fundaciones conventuales ni en todas las órdenes religiosas.

${ }^{74}$ Aporta la referencia de este debate, J. C. Vizuete MendozA «Una religión áspera en principios de reformación». Los carmelitas descalzos en Castilla, 1570-1600», en Teresianum, XLVI (1995). Pp. 543-582. 